\title{
REVIEW
}

Open Access

\section{Efficacy and safety of gout flare prophylaxis and therapy use in people with chronic kidney disease: a Gout, Hyperuricemia and Crystal-Associated Disease Network (G-CAN)-initiated literature review}

Huai Leng Pisaniello ${ }^{1}$, Mark C. Fisher ${ }^{2,3}$, Hamish Farquhar ${ }^{4}$, Ana Beatriz Vargas-Santos ${ }^{5}$, Catherine L. Hill, ${ }^{1,6}$ Lisa K. Stamp ${ }^{4}$ and Angelo L. Gaffo ${ }^{7,8^{*}}$

\begin{abstract}
Gout flare prophylaxis and therapy use in people with underlying chronic kidney disease (CKD) is challenging, given limited treatment options and risk of worsening renal function with inappropriate treatment dosing. This literature review aimed to describe the current literature on the efficacy and safety of gout flare prophylaxis and therapy use in people with CKD stages 3-5. A literature search via PubMed, the Cochrane Library, and EMBASE was performed from 1 January 1959 to 31 January 2018. Inclusion criteria were studies with people with gout and renal impairment (i.e. estimated glomerular filtration rate (eGFR) or creatinine clearance $(\mathrm{CrCl})<60 \mathrm{ml} / \mathrm{min} / 1.73 \mathrm{~m}^{2}$ ), and with exposure to colchicine, interleukin-1 inhibitors, non-steroidal anti-inflammatory drugs (NSAIDs), and glucocorticoids. All study designs were included. A total of 33 studies with efficacy and/or safety analysis stratified by renal function were reviewed-colchicine $(n=20)$, anakinra $(n=7)$, canakinumab $(n=1)$, NSAIDs $(n=3)$, and glucocorticoids $(n=2)$. A total of 58 studies reported these primary outcomes without renal function stratificationcolchicine $(n=29)$, anakinra $(n=10)$, canakinumab $(n=6)$, rilonacept $(n=2)$, NSAIDs $(n=1)$, and glucocorticoids $(n=10)$. Most clinical trials excluded study participants with severe CKD (i.e. eGFR or $\mathrm{CrCl}$ of $<30 \mathrm{~mL} / \mathrm{min} / 1.73 \mathrm{~m}^{2}$ ). Information on the efficacy and safety outcomes of gout flare prophylaxis and therapy use stratified by renal function is lacking. Clinical trial results cannot be extrapolated for those with advanced CKD. Where possible, current and future gout flare studies should include patients with CKD and with study outcomes reported based on renal function and using standardised gout flare definition.
\end{abstract}

Keywords: Gout, Gout flare, Colchicine, Corticosteroids, Non-steroidal anti-inflammatory, Interleukin 1 inhibitors, Treatment

\footnotetext{
* Correspondence: agaffo@uabmc.edu

${ }^{7}$ Division of Rheumatology and Clinical Immunology, University of Alabama,

1720 2nd Avenue South, Birmingham, AL 35294, USA

${ }^{8}$ Birmingham VA Medical Center, Birmingham, USA

Full list of author information is available at the end of the article
}

C C The Author(s). 2021 Open Access This article is licensed under a Creative Commons Attribution 4.0 International License, which permits use, sharing, adaptation, distribution and reproduction in any medium or format, as long as you give appropriate credit to the original author(s) and the source, provide a link to the Creative Commons licence, and indicate if changes were made. The images or other third party material in this article are included in the article's Creative Commons licence, unless indicated otherwise in a credit line to the material. If material is not included in the article's Creative Commons licence and your intended use is not permitted by statutory regulation or exceeds the permitted use, you will need to obtain permission directly from the copyright holder. To view a copy of this licence, visit http://creativecommons.org/licenses/by/4.0/ The Creative Commons Public Domain Dedication waiver (http://creativecommons.org/publicdomain/zero/1.0/) applies to the data made available in this article, unless otherwise stated in a credit line to the data. 


\section{Background}

Gout, a highly prevalent inflammatory arthritis worldwide, is often linked with renal impairment, among all other comorbidities clustered within the term 'metabolic syndrome' [1, 2]. For instance, in a nationwide US representative study, $19.9 \%$ of adults with gout had CKD $\geq$ stage 3 (i.e. estimated glomerular filtration rate (eGFR) of $<60 \mathrm{~mL} / \mathrm{min} / 1.73 \mathrm{~m}^{2}$ ) compared with $5.2 \%$ of adults without gout [3]. Gout is also highly prevalent in individuals with pre-existing CKD. In an age-standardised gout prevalence study in the USA, nearly one-fourth of adults with CKD $\geq$ stage 3 reported having gout in comparison with $2.9 \%$ individuals with normal renal function [4]. The degree of renal impairment, especially in advanced $C K D$, invariably plays a major role in the treatment decision-making when managing gout.

Gout flares, when inadequately treated, can have a profound impact on physical functioning and quality of life [5]. According to the 2020 American College of Rheumatology (ACR) guideline, colchicine, non-steroidal anti-inflammatory drugs (NSAIDs), and parenteral/oral glucocorticoids are recommended as the preferred firstline treatment options for managing gout flares [6, 7]. These anti-inflammatory treatment options are also recommended as short-term prophylaxis for when commencing urate-lowering therapy (ULT) [6, 7]. However, the use of gout flare prophylaxis and therapy in people with CKD is not always straightforward. In the context of minimal or absence of residual renal function, treatment options for gout flare are limited, with potential risks of further renal impairment. Renally adjusted dosing is often required in people with CKD, although there is no specific evidence-based guidance in monitoring the efficacy and safety of the treatment used. Therefore, clinicians often remain judicious when facing this common clinical conundrum in the management of gout flares. It is reassuring that, based on a recent systematic review, colchicine use is relatively safe in all possible clinical indications, with diarrhoea and gastrointestinal symptoms being the most commonly reported adverse events [8]. However, no conclusion could be precisely drawn from this review on the safety profile of colchicine use in people with CKD [8]. Overall, for all anti-inflammatory drugs used for gout flare, lack of consensus on the appropriate dosing and treatment monitoring for this highrisk comorbid population remains. The extent of this deficiency in the literature in terms of the efficacy and safety data for gout flare prophylaxis and therapy is unknown.

Accordingly, in parallel with the mission of the Gout, Hyperuricemia and Crystal-Associated Disease Network (G-CAN), this G-CAN-initiated literature review aims to identify all available literature on gout flare prophylaxis and therapy use in people with CKD stages $3-5$. In detail, we aim to explore the best available evidence that we currently have on the efficacy and safety of gout flare prophylaxis and therapy in this high-risk comorbid population, alongside the identification of important key areas for future research on this issue.

\section{Methods}

This literature review was conducted in accordance to the Preferred Reporting Items for Systematic Reviews and Meta-Analyses (PRISMA) guidelines.

\section{Literature search strategy}

A literature search in PubMed, The Cochrane Library, and EMBASE was conducted from 1 January 1959 to 27 June 2017. A subsequent search from 28 June 2017 to 31 January 2018 was updated to capture any additional studies published during the review process. We included all available gout flare prophylaxis and therapy use in clinical trials and real-world practice, which were colchicine, NSAIDs, glucocorticoids, and interleukin-1 (IL-1) inhibitors such as anakinra, canakinumab, and rilonacept.

In detail, literature search combining gout with either gout flare prophylaxis/therapy and CKD was performed separately to the literature search combining either gout flare prophylaxis/therapy and renal replacement therapy (i.e. haemodialysis and peritoneal dialysis). These two literature searches were subsequently merged prior to the screening phase. This search strategy was applied to all gout flare prophylaxis/therapy, except for glucocorticoids. The initial search attempt in crossing the glucocorticoid-related search terms with renal-related terms led to an excessive number of irrelevant search results. Therefore, for glucocorticoid-related literature search, the search term was only crossed against gout terms, and not with any renal-related terms. The search strategies for each database were outlined in Supplementary Table 1.

\section{Eligibility criteria and study selection}

We included studies which fulfil the following criteria: people diagnosed with gout, with $\mathrm{CKD} \geq$ stage 3 (i.e. eGFR or creatinine clearance $(\mathrm{CrCl})$ of $<60 \mathrm{~mL} / \mathrm{min} /$ $1.73 \mathrm{~m}^{2}$ ), and with exposure to the gout flare prophylaxis/therapy of interest. Only studies published in English were included. Studies in the form of case reports or case series as well as abstracts from the ACR and the European League Against Rheumatism (EULAR) were included for screening.

We excluded studies if the primary study population had a diagnosis other than gout, studies with inadequate or absence of information on the renal function (i.e. absence of CKD stage or eGFR/CrCl measure) and/or on the study drug of interest, and studies that included 
people with normal renal function or experiencing acute renal failure. In addition, studies published in the form of letters, editorials, opinions, review articles, and studies with animal-, basic science- or laboratory-based focus were excluded.

Study title and abstract screening for eligible studies was independently performed by two reviewers (HLP and CLH for colchicine and IL-1 inhibitors; MCF and AG for NSAIDs and glucocorticoids). Full-text screening for eligible studies for data extraction was independently performed by two reviewers in similar arrangement. Any discrepancy identified during the screening phase was discussed to reach consensus.

\section{Data extraction}

Relevant data for eligible studies were extracted independently by two reviewers (HLP and CLH for colchicine and IL-1 inhibitors; MCF and AG for NSAIDs and glucocorticoids). The extracted data included the primary author, year of study, trial name (where applicable), study design, and sample size. The extracted outcome data included the efficacy of the drug of interest (defined as the clinical resolution of gout flare or absence of gout flare during concomitant ULT use) and/or the safety profile of the drug of interest (defined as adverse events observed in the presence of active use of gout flare prophylaxis/therapy). Where applicable, we extracted studies reporting these outcome data as stratified by renal function. Discrepancies among the reviewers during this data extraction phase were minimal and were resolved by discussion.

\section{Analyses}

The eligible studies were analysed in terms of their overall study characteristics, sample size, drug indication (i.e. either as gout flare prophylaxis or as gout flare treatment), and dosages, and the efficacy and safety outcomes for the study drug of interest and the corresponding renal function stratification, where applicable. We were not able to summarise these studies quantitatively due to the heterogeneity nature of the studies included.

\section{Results}

An overview for all included studies was outlined in Table 1. Herein, results for each gout flare prophylaxis/ therapy with efficacy and safety outcome data stratified by renal function were presented in the main text and were summarised in Table 2. Specifically, the details for drug indication and drug dosage were reported in Table 2. For studies with outcome data reported without any renal function stratification, these were summarised separately in the Supplementary Materials.

\section{Colchicine}

A total of 2325 studies of colchicine use were identified, as summarised in a PRISMA flowchart of the literature search (Supplementary Figure 1), and a final total of 49 studies were eligible for data extraction [9-57]. Twenty of these 49 studies, which were mostly case series or case reports, described the efficacy and/or safety outcomes of colchicine use stratified by renal function, as summarised in Tables 2 and 3, respectively [17, 18, 20, $22,24,28,29,31-33,35-37,39,44,46,49,53,55,57]$. The remaining 29 studies reported efficacy and/or safety outcomes of colchicine use without renal function stratification, as summarised in Supplementary Table 2 and Supplementary Table 3, respectively $[9-16,19,21,23$, 25-27, 30, 34, 38, 40-43, 45, 47, 48, 50-52, 54, 56].

\section{Studies of colchicine use with analyses stratified by renal function}

These 20 studies included 1 single-centre audit, 3 case series, and 16 case reports, with a total of 43 study participants. Varying patterns in colchicine dosing amount and frequency as well as varying routes of drug administration were seen across these studies. Only 5 studies reported efficacy outcome data stratified by renal function, although no definitive conclusion could be drawn due to their heterogenous study characteristics and the quality of the evidence was low [18, 33, 44, 53, 55].

For the safety outcome, all studies reported varying level of transient change in renal function during colchicine use as well as after drug cessation. Fifteen studies reported colchicine-induced neuromyopathy and rhabdomyolysis $[18,20,24,29,31,32,35-37,39,44,46$, $49,53,55]$. Nine studies reported colchicine toxicity secondary to drug-drug interaction with statin, cyclosporin, clarithromycin, and hepatitis $\mathrm{C}$ treatments (i.e. sofosbuvir/ledipasvir) [17, 18, 28, 29, 31, 32, 36, 46, 49]. It was unclear from these studies if the reported adverse events were directly attributed to the colchicine use.

\section{Studies of colchicine use without analyses stratified by renal function}

These 29 studies included 2 single-centre randomised controlled trials (RCTs), 1 post hoc analysis of 3 different ULT-related RCTs, 1 post hoc analysis of a crosssectional study, one case-control study, 2 retrospective observational studies, 4 audits, 8 case series, and 10 case reports. All studies included study participants with varying degree of baseline renal impairment, and only pooled efficacy and safety outcome data were presented, without any renal function stratification in the outcome reporting. Furthermore, in studies using colchicine as gout flare prophylaxis, study participants with eGFR of $<30 \mathrm{~mL} / \mathrm{min} / 1.73 \mathrm{~m}^{2}$ were excluded, as evident in the 
Table 1 An overview of efficacy and safety outcome reporting of gout flare prophylaxis and therapy use (with and without renal function stratification)

\begin{tabular}{|c|c|c|c|c|c|c|c|c|}
\hline \multirow[t]{2}{*}{$\begin{array}{l}\text { First Author (Year) } \\
\text { (Trial Name) }\end{array}$} & \multirow[t]{2}{*}{ Study Design } & \multicolumn{4}{|c|}{$\begin{array}{l}\text { Number of participants by eGFR/CrCl } \\
\text { at baseline }\left(\mathrm{mL} / \mathrm{min} / 1.73 \mathrm{~m}^{2}\right)\end{array}$} & \multirow[t]{2}{*}{$\begin{array}{l}\text { Total, } \\
\mathrm{n}\end{array}$} & \multicolumn{2}{|c|}{$\begin{array}{l}\text { Primary outcome } \\
\text { data reporting } \\
\text { with stratified renal } \\
\text { function }=\text { Yes } \\
\text { without stratified renal } \\
\text { function }=\text { No }\end{array}$} \\
\hline & & $\geq 90$ & $60-90$ & $30-60$ & $<30$ & & Efficacy & Safety \\
\hline \multicolumn{9}{|l|}{ COLCHICINE } \\
\hline AHERN 1987 [9] & RCT (single-centre) & 22 & & & & 22 & No & No \\
\hline BORSTAD 2004 [10] & RCT (single-centre) & 14 & & & & 14 & No & No \\
\hline $\begin{array}{l}\text { WORTMANN } 2010 \text { (FACT, } \\
\text { APEX, CONFIRMS) [11] }\end{array}$ & $\begin{array}{l}\text { Three RCTs } \\
\text { (post-hoc analyses) }\end{array}$ & $\begin{array}{l}371(F) ; \\
541(A) ; \\
786(C)\end{array}$ & $\begin{array}{l}295(F) ; \\
154(A) ; \\
402(C)\end{array}$ & $\begin{array}{l}94(\mathrm{~F}) \\
154(\mathrm{~A}) ; \\
402(\mathrm{C})\end{array}$ & & $\begin{array}{l}760(F) ; \\
1072(A) ; \\
2269(C)\end{array}$ & No & No \\
\hline $\begin{array}{l}\text { PASCART 2016 } \\
\text { (GOSPEL 2) [12] }\end{array}$ & $\begin{array}{l}\text { Cross-sectional study } \\
\text { (post-hoc analysis) }\end{array}$ & 158 & 59 & 45 & 2 & 264 & No & No \\
\hline SOLAK 2014 [13] & Case-control & & & & 1 & 1 & No & No \\
\hline HUNG 2005 [14] & $\begin{array}{l}\text { Retrospective } \\
\text { observational } \\
\text { (single-centre) }\end{array}$ & \multicolumn{4}{|c|}{$\begin{array}{l}29 \text { (concomitant arm) } \\
\text { vs } 8 \text { (sequential arm) }\end{array}$} & 37 & No & No \\
\hline KWON 2017 [15] & $\begin{array}{l}\text { Retrospective } \\
\text { observational } \\
\text { (single-centre) }\end{array}$ & \multicolumn{4}{|c|}{$\begin{array}{l}36 / 188 \\
\text { (colchicine with statin arm) } \\
\text { vs } 41 / 486 \\
\text { (colchicine without statin arm) }\end{array}$} & 77 & No & No \\
\hline AKAR 2001 [16] & Case report & & & & 1 & 1 & No & No \\
\hline AKDAG 2006 [17] & Case report & & & & 1 & 1 & No & Yes \\
\hline ALAYLI 2005 [18] & Case report & & & 1 & & 1 & Yes & Yes \\
\hline ALTIPARMAK 2002 [19] & Case series & & & & 1 & 1 & No & No \\
\hline ALTMAN 2007 [20] & Case report & & & 1 & & 1 & No & Yes \\
\hline BAKER 2004 [21] & Case report & & & 1 & & 1 & No & No \\
\hline BONNEL 2002 [22] & Case series & & & & 1 & 1 & No & Yes \\
\hline BOOMERSHINE 2002 [23] & Case report & & & & 1 & 1 & No & No \\
\hline BOUQUIÉ 2011 [24] & Case report & & & 1 & & 1 & No & Yes \\
\hline CHENG 2005 [25] & Case series & & & & 1 & 1 & No & No \\
\hline CHOI 1999 [26] & Case report & & & & 1 & 1 & No & No \\
\hline DIXON 2001 [27] & Case report & & & 1 & & 1 & No & No \\
\hline ELEFTHERIOU 2008 [28] & Case report & & & & 1 & 1 & No & Yes \\
\hline GARROUSTE 2012 [29] & Case report & & & & 1 & 1 & No & Yes \\
\hline HSU 2002 [30] & Case report & & & & 1 & 1 & No & No \\
\hline HUH 2013 [31] & Case report & & & 1 & & 1 & No & Yes \\
\hline JUSTINIANO 2007 [32] & Case report & & & 1 & & 1 & No & Yes \\
\hline KUBLER 2000 [33] & Case report & & & & 1 & 1 & Yes & Yes \\
\hline KUNCL 1987 [34] & Case series & 12 & & & & 12 & No & No \\
\hline LAl 2006 [35] & Case report & & & & 1 & 1 & No & Yes \\
\hline LEE 1997 [36] & Case report & & & 1 & & 1 & No & Yes \\
\hline LY 2007 [37] & Audit (single centre) & & 22 & & & 22 & No & Yes \\
\hline MARCINIAK 2016 [38] & Case report & & & 1 & & 1 & No & No \\
\hline MEDANI 2016 [39] & Case series & & & 1 & 1 & 2 & No & Yes \\
\hline MONTSENY 1996 [40] & Case series & & & & 4 & 4 & No & No \\
\hline MORRIS 2003 [41] & Case series & & & & 1 & 1 & No & No \\
\hline
\end{tabular}


Table 1 An overview of efficacy and safety outcome reporting of gout flare prophylaxis and therapy use (with and without renal function stratification) (Continued)

\begin{tabular}{|c|c|c|c|c|c|c|c|c|}
\hline \multirow[t]{2}{*}{$\begin{array}{l}\text { First Author (Year) } \\
\text { (Trial Name) }\end{array}$} & \multirow[t]{2}{*}{ Study Design } & \multicolumn{4}{|c|}{$\begin{array}{l}\text { Number of participants by eGFR/CrCl } \\
\text { at baseline }\left(\mathrm{mL} / \mathrm{min} / 1.73 \mathrm{~m}^{2}\right)\end{array}$} & \multirow[t]{2}{*}{$\begin{array}{l}\text { Total, } \\
\text { n }\end{array}$} & \multicolumn{2}{|c|}{$\begin{array}{l}\text { Primary outcome } \\
\text { data reporting } \\
\text { with stratified renal } \\
\text { function }=\text { Yes } \\
\text { without stratified renal } \\
\text { function }=\text { No }\end{array}$} \\
\hline & & $\geq 90$ & $60-90$ & $30-60$ & $<30$ & & Efficacy & Safety \\
\hline MULLINS 2011 [42] & Audit (single centre) & 4 & 7 & 16 & 10 & 37 & No & No \\
\hline NASHEL 1982 [43] & Case series & & & & 2 & 2 & No & No \\
\hline NEUSS 1986 [44] & Case report & & & & 1 & 1 & Yes & Yes \\
\hline ORTEL 1974 [45] & Case report & & & 1 & & 1 & No & No \\
\hline PATEL 2016 [46] & Case report & & & 1 & & 1 & No & Yes \\
\hline PETERSEL 2007 [47] & Audit (single centre) & 38 & & & & 38 & No & No \\
\hline RANA 1997 [48] & Case series & & & 3 & & 3 & No & No \\
\hline RIEGER 1990 [49] & Case report & & & & 1 & 1 & No & Yes \\
\hline RUTKOVE 1996 [50] & Case series & & & & 4 & 4 & No & No \\
\hline SU 2015 [51] & Case report & & & & 1 & 1 & No & No \\
\hline VAN DER VALDEN 2008 [52] & Case report & & & & 1 & 1 & No & No \\
\hline WILBUR 2004 [53] & Case series & & & 1 & 1 & 2 & Yes & Yes \\
\hline WRIGHT 2017 [54] & Audit & 128 & & & & 128 & No & No \\
\hline YOON 2001 [55] & Case report & & & 1 & & 1 & Yes & Yes \\
\hline YU 2018 [56] & Audit & 9 & & & & 9 & No & No \\
\hline ZAGLER 2009 [57] & Case report & & & 1 & & 1 & No & Yes \\
\hline \multicolumn{9}{|l|}{ IL-1 INHIBITORS } \\
\hline SCHLESINGER 2011 [58] & $\begin{array}{l}\text { Phase } 2 R C T \text { - an extension of } \\
\text { a phase } 2 R C T \text { by So et al., } 2010 \\
\text { (multi-centre) }\end{array}$ & 95 & & & & 95 & No & No \\
\hline $\begin{array}{l}\text { SCHLESINGER } 2012 \\
\text { ( } \beta \text {-RELIEVED \& } \beta \text {-RELIEVED-II) } \\
{[59]}\end{array}$ & $\begin{array}{l}\text { Two phase } 3 \text { RCTs, followed } \\
\text { by extension studies for } \\
\text { both trials (multi-centre) }\end{array}$ & & 123 & 59 & & 182 & No & No \\
\hline SO 2007 [60] & $\begin{array}{l}\text { Pilot, open-labelled study } \\
\text { (single-centre) }\end{array}$ & 2 & 5 & 2 & 1 & 10 & No & No \\
\hline SO 2010 [61] & Phase 2 RCT (multi-centre) & 95 & & & & 95 & No & No \\
\hline SUNKUREDDI 2011 [62] & $\begin{array}{l}\text { Post-hoc analyses of the RCTs } \\
\text { ( } \beta \text {-RELIEVED \& } \beta \text {-RELIEVED-II) } \\
\text { ACR abstract }\end{array}$ & & 188 & & & 188 & No & No \\
\hline SUNKUREDDI 2013 [63] & $\begin{array}{l}\text { Post-hoc analyses of the RCTS } \\
\text { (B-RELIEVED \& } \beta \text {-RELIEVED-II) } \\
\text { EULAR abstract }\end{array}$ & & 65 & & & 65 & No & No \\
\hline SUNKUREDDI 2014 [64] & $\begin{array}{l}\text { Post-hoc analysis of } \\
\text { an RCT (multi-centre) } \\
\text { ACR abstract }\end{array}$ & & & 24 & & 24 & No & No \\
\hline TERKELTAUB 2009 [65] & Crossover trial (multi-centre) & 2 & & & & 2 & No & No \\
\hline TERKELTAUB 2012 [66] & $\begin{array}{l}\text { Post-hoc analyses of RCTs } \\
\text { (PRE-SURGE 1, PRE-SURGE } 2 \\
\text { and RE-SURGE) } \\
\text { ACR abstract }\end{array}$ & & 624 & 103 & & 727 & No & No \\
\hline ADLER 2017 [67] & Case report & & & & 1 & 1 & Yes & No \\
\hline AOUBA 2015 [68] & Case series (single-centre) & 1 & 1 & 1 & & 3 & Yes & Yes \\
\hline BARTOV 2013 [69] & Case report & & & & 1 & 1 & Yes & Yes \\
\hline CHEN 2010 [70] & Case series (single-centre) & & 2 & 5 & 3 & 10 & No & No \\
\hline
\end{tabular}


Table 1 An overview of efficacy and safety outcome reporting of gout flare prophylaxis and therapy use (with and without renal function stratification) (Continued)

\begin{tabular}{|c|c|c|c|c|c|c|c|c|}
\hline \multirow[t]{2}{*}{$\begin{array}{l}\text { First Author (Year) } \\
\text { (Trial Name) }\end{array}$} & \multirow[t]{2}{*}{ Study Design } & \multicolumn{4}{|c|}{$\begin{array}{l}\text { Number of participants by eGFR/CrCl } \\
\text { at baseline }\left(\mathrm{mL} / \mathrm{min} / 1.73 \mathrm{~m}^{2}\right)\end{array}$} & \multirow[t]{2}{*}{$\begin{array}{l}\text { Total, } \\
\text { n }\end{array}$} & \multicolumn{2}{|c|}{$\begin{array}{l}\text { Primary outcome } \\
\text { data reporting } \\
\text { with stratified renal } \\
\text { function }=\text { Yes } \\
\text { without stratified renal } \\
\text { function }=\text { No }\end{array}$} \\
\hline & & $\geq 90$ & $60-90$ & $30-60$ & $<30$ & & Efficacy & Safety \\
\hline DIREZ 2012 [71] & Case report & & & & 1 & 1 & Yes & Yes \\
\hline DONMEZ 2014 [72] & Case report & & & 1 & & 1 & No & No \\
\hline FUNCK-BRENTANO 2011 [73] & Case report & & & & 1 & 1 & No & No \\
\hline GHOSH 2013 [74] & Case series (single-centre) & & & 5 & & 5 & No & No \\
\hline GRATTON 2009 [75] & Case report & & & & 1 & 1 & No & No \\
\hline LOUSTAU 2018 [76] & Case series (multi-centre) & & & 6 & 25 & 31 & Yes & Yes \\
\hline MAROTTO 2018 [77] & Case report & & & 1 & & 1 & Yes & Yes \\
\hline MCGONAGLE 2007 [78] & Case report & & & 1 & & 1 & No & No \\
\hline OTTAVIANI 2013 [79] & Case series (multi-centre) & & & 40 & & 40 & No & No \\
\hline PALMA 2016 [80] & $\begin{array}{l}\text { Case series (single-centre) } \\
\text { ACR abstract }\end{array}$ & & & 18 & & 18 & No & No \\
\hline PEREZ-RUIZ 2013 [81] & $\begin{array}{l}\text { Case series (single-centre) } \\
\text { EULAR abstract }\end{array}$ & 2 & & 6 & & 8 & Yes & Yes \\
\hline SINGH 2009 [82] & Case report & & & 1 & & 1 & No & No \\
\hline TRAN 2011 [83] & Case series & & & 1 & & 1 & Yes & No \\
\hline \multicolumn{9}{|c|}{ NON-STEROIDAL ANTI-INFLAMMATORY DRUGS } \\
\hline KAHL 1989 [84] & Case series & & & 1 & 1 & 2 & Yes & Yes \\
\hline MIKHNEVICH 2013 [85] & Case series & 82 & & 15 & & 97 & No & No \\
\hline SCHLONDORFF 1993 [86] & Case report & & 1 & & & 1 & Yes & Yes \\
\hline ZAGLER 2009 [57] & Case report & & & 1 & & 1 & Yes & Yes \\
\hline \multicolumn{9}{|l|}{ GLUCOCORTICOIDS } \\
\hline SUNKUREDDI 2014 [64] & $\begin{array}{l}\text { Post-hoc analysis of an } \\
\text { RCT (multi-centre) } \\
\text { ACR abstract }\end{array}$ & & & 24 & & 24 & No & No \\
\hline BAJAJ 2004 [87] & Case series (single-centre) & 4 & & 2 & 4 & 10 & No & No \\
\hline FARGETTI 2012 [88] & Case report & & & 1 & & 1 & No & No \\
\hline HAUSCH 1991 [89] & Case report & & & 1 & & 1 & No & No \\
\hline HILL 2008 [90] & Case report & & & & 1 & 1 & No & No \\
\hline KARIMZADEH 2009 [91] & Case report & & & 1 & & 1 & No & No \\
\hline MAEKAWA 2014 [92] & Case report & & & & 1 & 1 & No & No \\
\hline RICHETTE 2006 [93] & Case report & & & & 1 & 1 & No & No \\
\hline SARMENTO 2009 [94] & Case report & & & 1 & & 1 & No & No \\
\hline TAUSCHE 2011 [95] & Case report & & & 1 & & 1 & Yes & Yes \\
\hline UDAYAKUMAR 2010 [96] & Case report & & & 1 & & 1 & No & No \\
\hline ZAGLER 2009 [57] & Case report & & & 1 & & 1 & Yes & Yes \\
\hline
\end{tabular}

ACR: American College of Rheumatology; APEX: Allopurinol- and Placebo-Controlled, Efficacy Study of Febuxostat; CONFIRMS: A Phase 3, Randomised, Multicenter, Double-Blind, Allopurinol-Controlled Study Assessing the Efficacy and Safety of Oral Febuxostat in Subjects With Gout; CrCl: creatinine clearance; eGFR: estimated glomerular filtration rate; EULAR: European League Against Rheumatism; FACT: Febuxostat Versus Allopurinol Control Trial in Subjects With Gout; GOSPEL 2: subgroup analysis of GOSPEL (goutte et observation des stratégies de prise en charge en médecine ambulatoire) survey; IL-1: interleukin-1; PRE-SURGE 1: Preventative Study Against Urate-Lowering Drug-Induced Gout Exacerbations 1; PRE-SURGE 2: Preventative Study Against Urate-Lowering Drug-Induced Gout Exacerbations; RCT: randomised controlled trial; RE-SURGE: Review of Safety Using Rilonacept in Preventing Gout Exacerbations; $\beta$-RELIEVED \& $\beta$-RELIEVED-II: two phase three randomised studies (response in acute flare and in prevention of episodes of re-flare in gout) Rows set in italics include studies described in the supplementary materials 


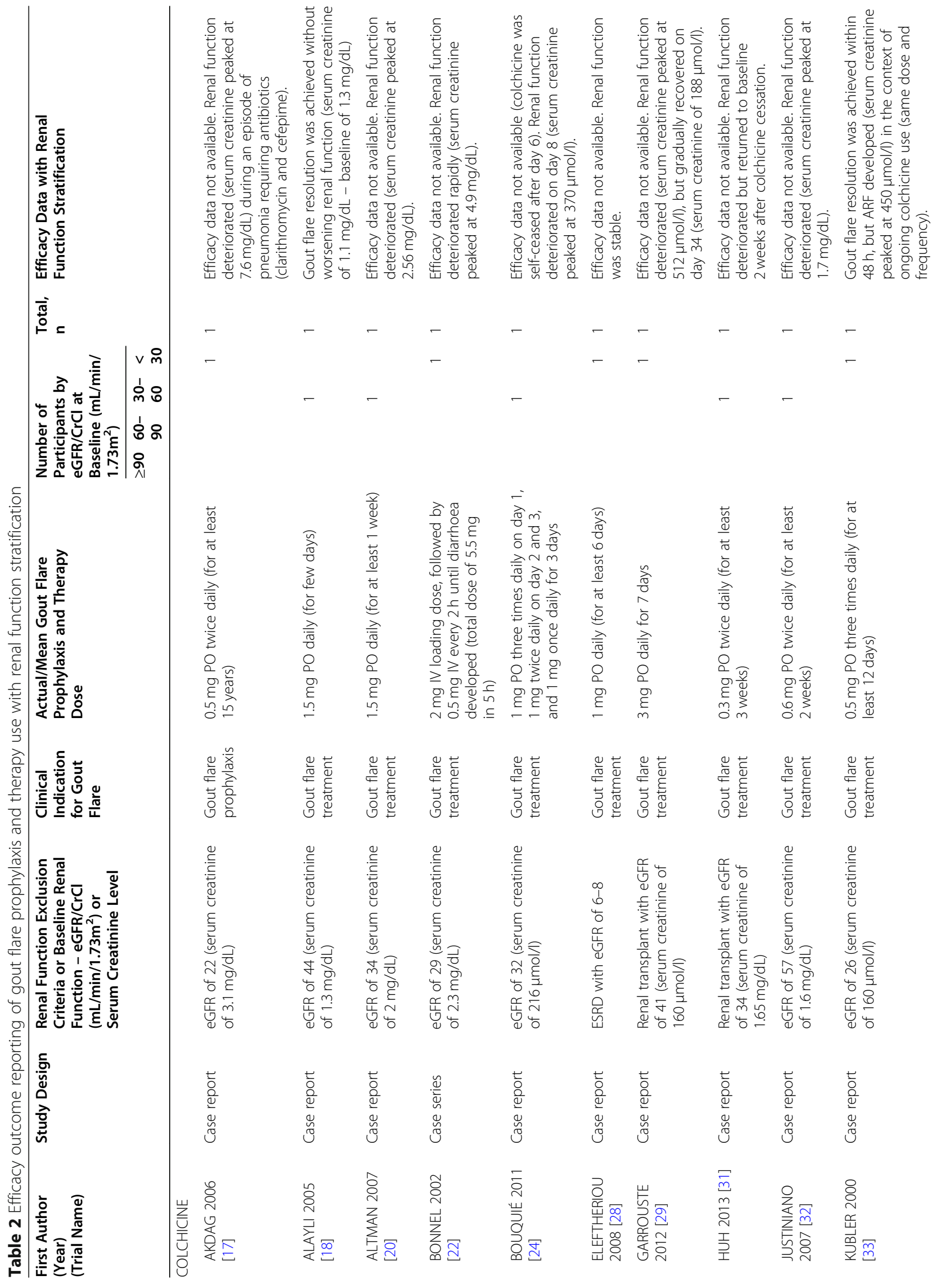




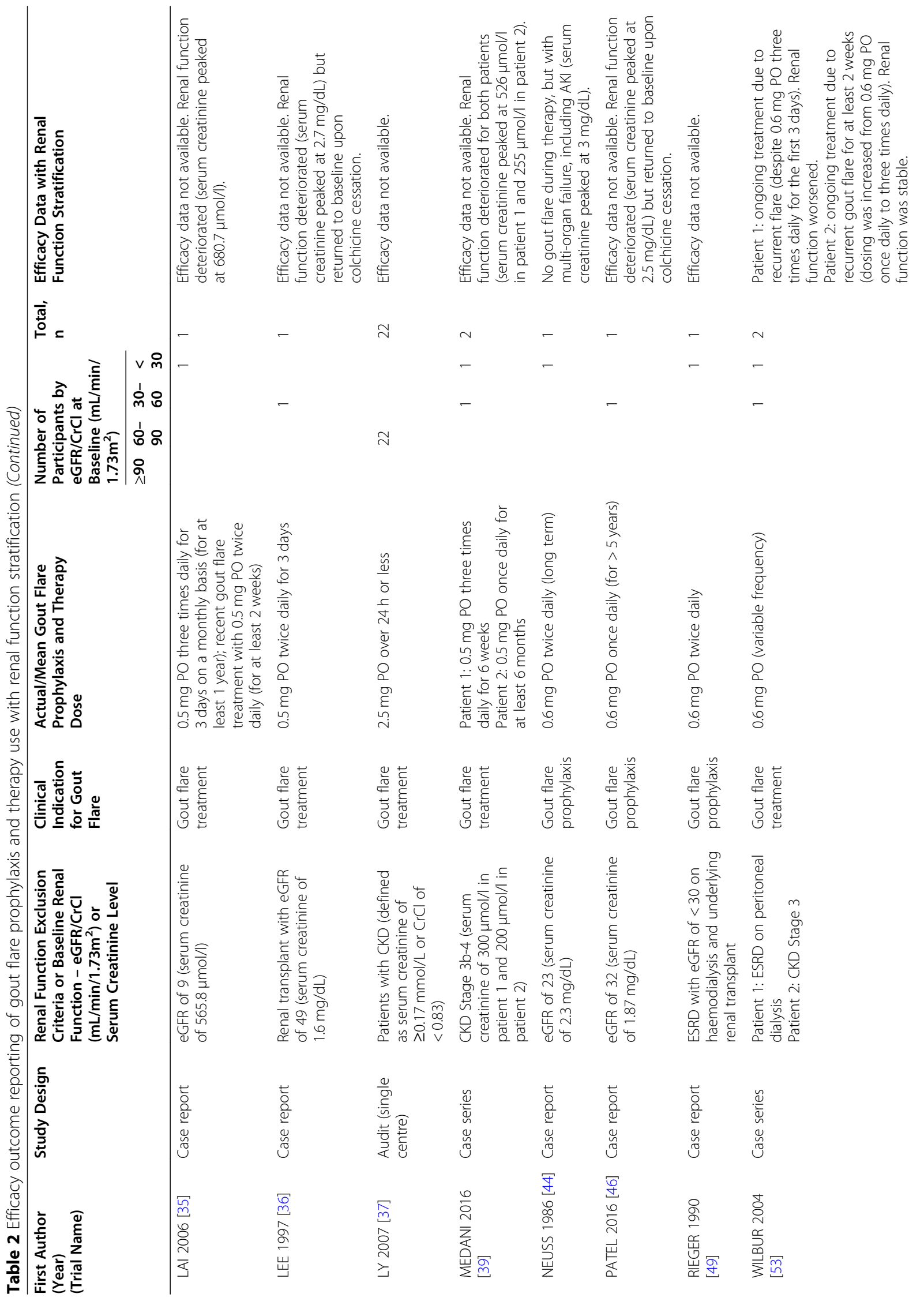




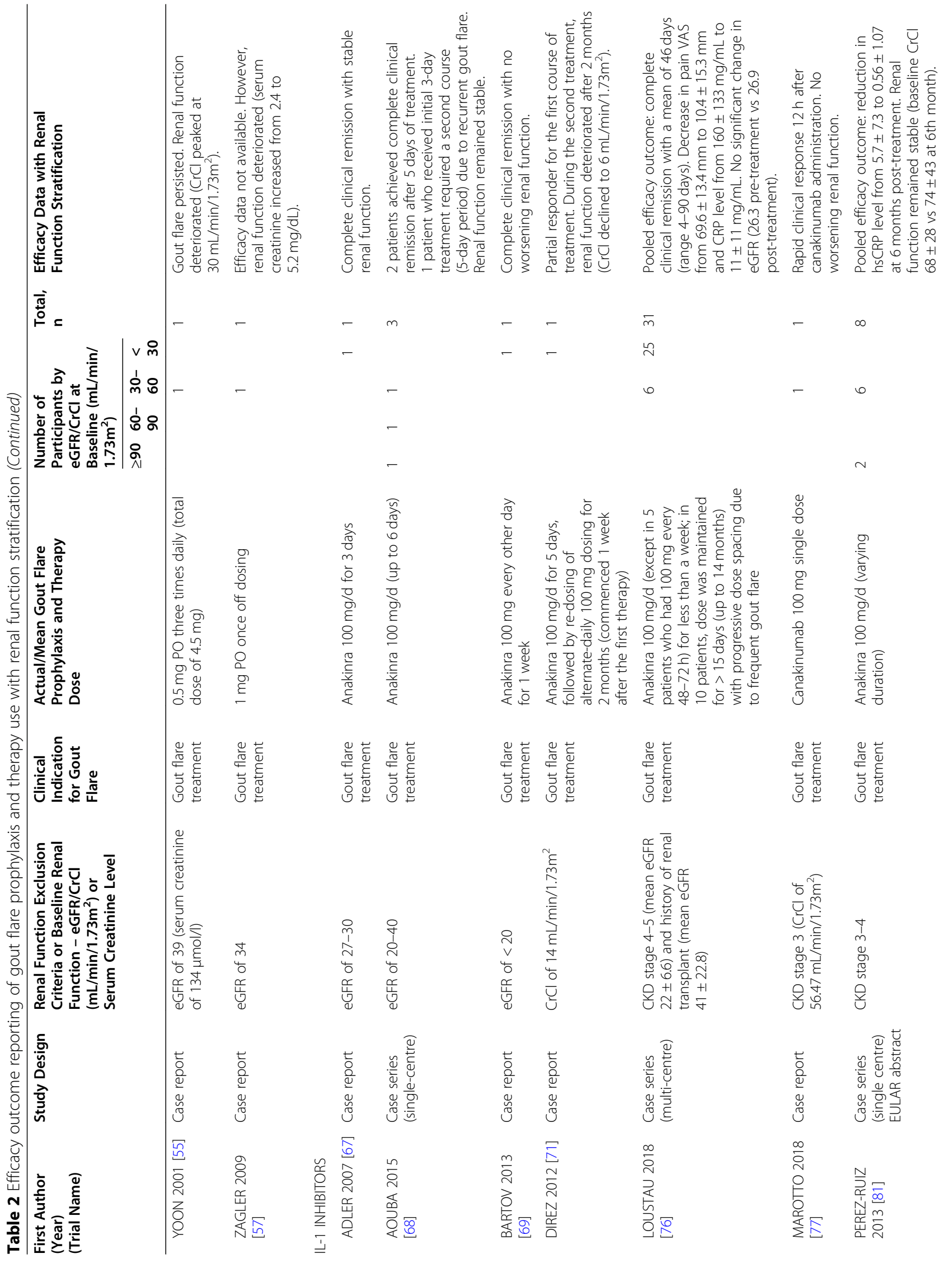




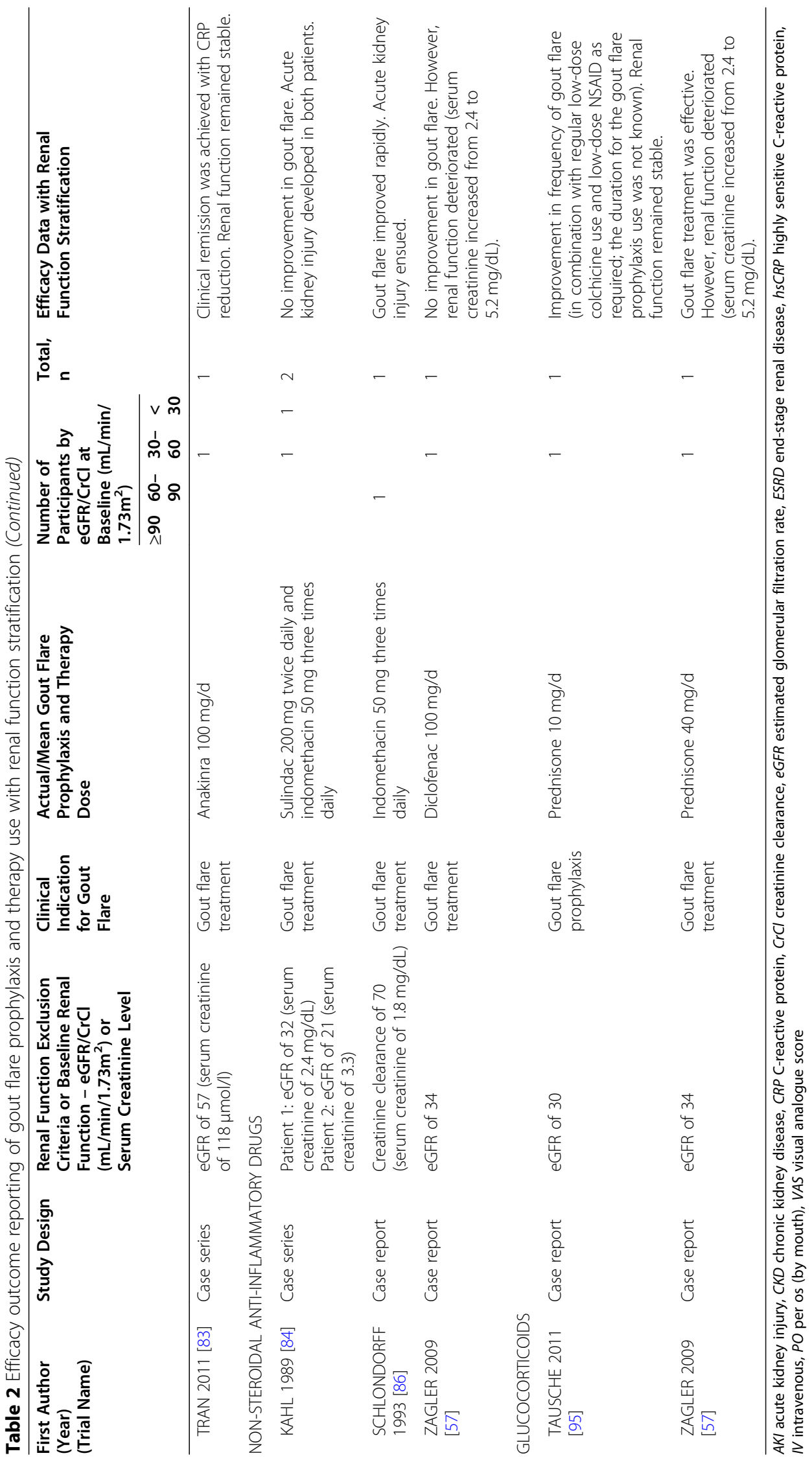


Table 3 Safety outcome reporting of gout flare prophylaxis and therapy use with renal function stratification

\begin{tabular}{|c|c|c|}
\hline $\begin{array}{l}\text { First Author (Year) } \\
\text { (Trial Name) }\end{array}$ & $\begin{array}{l}\text { Adverse/Serious Adverse Events } \\
\text { Reported by Renal Function }\end{array}$ & Notable Findings \\
\hline \multicolumn{3}{|l|}{ COLCHICINE } \\
\hline AKDAG 2006 [17] & Yes & $\begin{array}{l}\text { Colchicine toxicity in the context of antibiotic use (clarithromycin } \\
\text { and cefepime) for pneumonia. Besides worsening renal function, } \\
\text { there was associated mild pancytopaenia and liver impairment. }\end{array}$ \\
\hline ALAYLI 2005 [18] & Yes & Colchicine neuromyopathy in the context of concomitant statin use. \\
\hline ALTMAN 2007 [20] & Yes & Colchicine-induced rhabdomyolysis. \\
\hline BONNEL 2002 [22] & Yes & $\begin{array}{l}\text { Fatal colchicine toxicity with rapidly deteriorating renal function } \\
\text { and death. }\end{array}$ \\
\hline BOUQUIÉ 2011 [24] & Yes & $\begin{array}{l}\text { Colchicine-induced rhabdomyolysis with acute decompensation of } \\
\text { pre-existing double heart/lung transplant and multi-organ failure. }\end{array}$ \\
\hline ELEFTHERIOU 2008 [28] & Yes & $\begin{array}{l}\text { Colchicine toxicity with multi-organ failure in the context of } \\
\text { concomitant long-term cyclosporin therapy for heart transplant. }\end{array}$ \\
\hline GARROUSTE 2012 [29] & Yes & $\begin{array}{l}\text { Colchicine toxicity with neuromyopathy and multi-organ failure in } \\
\text { the context of concomitant long-term cyclosporin use for renal } \\
\text { transplant. }\end{array}$ \\
\hline HUH 2013 [31] & Yes & $\begin{array}{l}\text { Colchicine toxicity with gastrointestinal symptoms and } \\
\text { neuromyopathy in the context of concomitant long-term } \\
\text { cyclosporin use for renal transplant and statin use. }\end{array}$ \\
\hline JUSTINIANO 2007 [32] & Yes & $\begin{array}{l}\text { Colchicine-induced rhabdomyolysis in the context of concomitant } \\
\text { statin use. }\end{array}$ \\
\hline KUBLER 2000 [33] & Yes & Fatal colchicine toxicity with multi-organ failure and death. \\
\hline LAl 2006 [35] & Yes & Colchicine neuromyopathy. \\
\hline LEE 1997 [36] & Yes & $\begin{array}{l}\text { Acute myopathy in the context of concomitant cyclosporin use for } \\
\text { renal transplant. }\end{array}$ \\
\hline LY 2007 [37] & Yes & $\begin{array}{l}\text { One patient with CKD (serum creatinine of } 0.21 \mathrm{mmol} / \mathrm{L} \text { ) developed } \\
\text { colchicine myopathy. }\end{array}$ \\
\hline MEDANI 2016 [39] & Yes & Colchicine neuromyopathy. \\
\hline NEUSS 1986 [44] & Yes & $\begin{array}{l}\text { Fatal colchicine toxicity with myopathy, multi-organ failure, severe } \\
\text { neutropaenia with associated disseminated candidiasis and death. }\end{array}$ \\
\hline PATEL 2016 [46] & Yes & $\begin{array}{l}\text { Colchicine-induced rhabdomyolysis in the context of statin use and } \\
\text { initiation of sofosbuvir/ledipasvir therapy for Hepatitis } C \text {. }\end{array}$ \\
\hline RIEGER 1990 [49] & Yes & $\begin{array}{l}\text { Colchicine neuromyopathy in the context of acute stage of } \\
\text { post-renal transplant and cyclosporin use. }\end{array}$ \\
\hline WILBUR 2004 [53] & Yes & Colchicine neuromyopathy. \\
\hline YOON 2001 [55] & Yes & $\begin{array}{l}\text { Colchicine toxicity with associated pancytopaenia, neuromyopathy } \\
\text { and total alopecia. }\end{array}$ \\
\hline ZAGLER 2009 [57] & Yes & Colonic perforation and acute on chronic CKD. \\
\hline \multicolumn{3}{|l|}{ IL-1 INHIBITORS } \\
\hline ADLER 2007 [67] & No & Anakinra treatment: adverse event was not reported. \\
\hline AOUBA 2015 [68] & Yes & $\begin{array}{l}\text { Anakinra treatment: } 1 \text { patient with mild injection site reaction, } \\
\text { transient diffuse pruritus and episodic diarrhoea. }\end{array}$ \\
\hline BARTOV 2013 [69] & Yes & Anakinra treatment: adverse event was not observed. \\
\hline DIREZ 2012 [71] & Yes & Anakinra treatment: non-complicated neutropaenia. \\
\hline LOUSTAU 2018 [76] & Yes & $\begin{array}{l}\text { Anakinra treatment: } 1 \text { patient with an infection (nosocomial } \\
\text { pyelonephritis). No other adverse event was observed. }\end{array}$ \\
\hline MAROTTO 2018 [77] & Yes & Canakinumab treatment: adverse event was not observed. \\
\hline PEREZ-RUIZ 2013 [81] & Yes & $\begin{array}{l}\text { Anakinra treatment: } 1 \text { patient with recurrent heart failure. No other } \\
\text { adverse event was observed. }\end{array}$ \\
\hline TRAN 2011 [83] & Yes & Anakinra treatment: adverse event was not reported. \\
\hline
\end{tabular}


Table 3 Safety outcome reporting of gout flare prophylaxis and therapy use with renal function stratification (Continued)

\begin{tabular}{lll}
\hline $\begin{array}{l}\text { First Author (Year) } \\
\text { (Trial Name) }\end{array}$ & $\begin{array}{l}\text { Adverse/Serious Adverse Events } \\
\text { Reported by Renal Function }\end{array}$ & Notable Findings \\
\hline NON-STEROIDAL ANTI-INFLAMMATORY DRUGS & Acute kidney injury with sulindac and indomethacin use. \\
KAHL 1989 [84] & Yes & Acute kidney injury with indomethacin use. \\
SCHLONDORFF 1993 [86] & Yes & Colonic perforation and acute on chronic CKD. \\
ZAGLER 2009 [57] & Yes & \\
GLUCOCORTICOIDS & & Adverse event was not reported. \\
TAUSCHE 2011 [95] & No & Colonic perforation and acute on chronic CKD. \\
ZAGLER 2009 [57] & Yes &
\end{tabular}

CKD Chronic kidney disease

RCT by Borstad and colleagues and the post hoc study of 3 different ULT-related RCTs [10, 11].

\section{IL-1 inhibitors}

A total of 1067 studies of IL-1 inhibitor use were identified, as summarised in a PRISMA flowchart of the literature search (Supplementary Figure 2), and a final total of 26 studies were eligible for data extraction [58-83]. Eight of these 26 studies, which were mostly case series or case reports, described the efficacy and/or safety outcomes of IL-1 inhibitor use stratified by renal function, as summarised in Tables 2 and 3, respectively [67-69, $71,76,77,81,83]$. The remaining 18 studies reported efficacy and/or safety outcomes of IL-1 inhibitor use without renal function stratification, as summarised in Supplementary Table 2 and Supplementary Table 3 respectively [58-66, 70, 72-75, 78-80, 82]. Overall, there were 17 studies of anakinra use, 7 studies of canakinumab use, and 2 studies of rilonacept use.

\section{Studies of IL-1 inhibitor use with analyses stratified by renal} function

These 8 studies of IL-1 inhibitor use as gout flare therapy included 4 case series and 3 case reports of anakinra use, and 1 case report of canakinumab use. A standard 100-mg dosing was routinely observed in studies of anakinra use, albeit varying dose frequency and duration in the context of varying degree of renal impairment and the duration of gout flare. Six out of 7 studies of anakinra use demonstrated stable renal function during treatment irrespective of pre-existing CKD [67-69, 76, 81, 83]. One case report of anakinra use described a decline in renal function [71]. In terms of anakinra's safety profile, 4 studies reported non-fatal infection-related adverse events $[68,71,76$, 81]. The case report on canakinumab use described good efficacy in treating gout flare without any compromise in renal function or in safety signal [77]. No definitive conclusion on IL-1 inhibitor use in CKD could be drawn due to the low quality of evidence for these studies.

\section{Studies of IL-1 inhibitor use without analyses stratified by renal function}

There were 10 studies of anakinra use (1 singlecentre open-label clinical trial, 4 case series, and 5 case reports) $[60,70,72-75,78-80,82]$. In the openlabel clinical trial of anakinra use by So and colleagues, study participants with advanced CKD (i.e. eGFR of $<30 \mathrm{~mL} / \mathrm{min} / 1.73 \mathrm{~m}^{2}$ ) were excluded from the study and the efficacy and/or safety outcomes for CKD subgroups were not presented, as only pooled results were reported [60].

All RCTs of canakinumab use, described in 6 different published articles, excluded individuals with advanced CKD (i.e. eGFR of $<30 \mathrm{~mL} / \mathrm{min} / 1.73 \mathrm{~m}^{2}$ ) [58, 59, 6164]. These studies included a multi-centre phase 2 trial evaluating the efficacy of canakinumab of varying doses (with the initial study results reported by So and colleagues, followed by the remaining study results reported by Schlesinger and colleagues) [58, 61], and the $\beta$ RELIEVED and $\beta$-RELIEVED II randomised trials (with study results reported in 3 separate published articles) $[59,62,63]$. In the $\beta$-RELIEVED and $\beta$-RELIEVED II randomised trials, although the analyses were performed on a subgroup of participants with CKD $\geq$ stage 3 , pooled outcome results were presented [59, 62, 63]. Similarly, for the $\beta$-RELIEVED and $\beta$-RELIEVED II randomised trials looking at different canakinumab formulations, pooled outcome results for CKD subgroup were presented [64].

Two clinical trials of rilonacept use (1 crossover trial and 1 post hoc analysis of PRE-SURGE 1, PRESURGE 2, and RE-SURGE clinical trials) also similarly excluded study participants with $C K D \geq$ stage 3 and only pooled outcome results were presented $[65,66]$. 


\section{NSAIDs}

Using the search terms as outlined in Supplementary Table 1, 1835 studies of NSAID use were initially identified, as summarised in a PRISMA flowchart summary (Supplementary Figure 3). After a sequential review of the title, abstract, and full-text, a final total of 4 studies of NSAID use were included for data extraction, with 3 studies reported efficacy and/or safety outcomes stratified by renal function and the remaining 1 study had study outcomes reported without renal function stratification [57, 84-86]. These 4 studies largely aimed at showcasing the potential risk for nephrotoxicity with NSAID use as gout flare prophylaxis and therapy in patients with CKD.

\section{Studies of NSAID use with analyses stratified by renal function}

There were 1 case series and 2 case reports of NSAID use reporting study outcomes based on renal function (Tables 2 and 3) [57, 84, 86]. Of note, these studies documented the onset of acute kidney injury (AKI) with NSAID use in patients with gout flare and concomitant CKD. However, despite the eligibility for data extraction, these studies had insufficient number of patients and information to accurately ascertain the efficacy or toxicity of NSAID use in managing gout flares in patients with CKD.

\section{Studies of NSAID use without analyses stratified by renal function}

One case series, although without outcome results documented by renal function stratification, described an association between NSAID use and risk of developing AKI (Supplementary Table 2 and Supplementary Table 3) [85].

\section{Glucocorticoids}

Using the search terms as outlined in Supplementary Table 1, 1678 studies of glucocorticoid use were initially identified, as summarised in a PRISMA flowchart summary (Supplementary Figure 4). After a sequential review of the title, abstract and full-text, a final total of 12 studies were included for data extraction [57, 64, 8796]. Eleven out of these 12 studies were of case reports $(n=10)$ and of case series $(n=1)$ [57, 87-96]. Therefore, the evidence provided from these limited data did not allow any accurate conclusion drawn on the efficacy and/or safety of glucocorticoid use in gout flare and concomitant CKD. Only 2 studies reported efficacy and/or safety outcomes stratified by renal function and the remaining 10 study had study outcomes reported without renal function stratification.

\section{Studies of glucocorticoid use with analyses stratified by renal function}

Two case reports had outcome results stratified by renal function, but further conclusion could not be drawn due to the low level of evidence for these studies (Tables 2 and 3) $[57,95]$.

\section{Studies of glucocorticoid use without analyses stratified by renal function}

Ten studies of glucocorticoid use described outcome results without renal function stratification (Supplementary Table 2 and Supplementary Table 3) [64, 87-94, 96]. One single-centre case series by Bajaj and colleagues described a cohort of 10 lupus patients with gout flare, of which 8 of them were on varying doses of prednisone as gout flare therapy [87].

\section{Discussion}

This review explores the current literature on the efficacy and safety outcome data on the use of gout flare prophylaxis and therapy in people with CKD $\geq$ stage 3 . Without limiting the publication date and study design, we were able to capture all of the efficacy and/or safety data for different anti-inflammatory therapy used for gout flare in people with underlying renal impairment. Using the best evidence synthesis approach, we then extracted and summarised the outcome data for each study based on the presence or absence of renal function stratification. Overarchingly, this review has highlighted the absence of conclusive data on efficacy or safety in gout flare prophylaxis and therapy use in patients with underlying advanced CKD.

Although colchicine has been used for many years and remains a first-line anti-inflammatory drug for gout flare prophylaxis and therapy, we currently have insufficient data to adequately inform us on the efficacy and safety of using colchicine in people with gout and concomitant CKD. For instance, there are only 2 single-centre RCTs and 1 post hoc analysis study of three RCTs reporting on colchicine prophylactic use in people with underlying $\mathrm{CKD}$, although these clinical trials presented aggregated outcome results (i.e. without renal function stratification) for the efficacy and safety data on colchicine use in this subgroup, and these results are not necessarily informative for people with varying CKD stages. In addition, we have seen different results on the impact of gout flare treatment on renal function in case reports and case series. For instance, 12 studies reported deteriorated renal function with colchicine use $[17,20,22,24$, $32,33,35,39,44,53,55,57]$, whereas 7 other studies reported stable renal function with colchicine use $[18,28$, $29,31,36,46,53]$. As a result, given the underlying risk of bias on study quality for these studies, we cannot sufficiently conclude on the efficacy and/or safety outcomes 
on colchicine use for people with gout and concomitant CKD. In the AGREE clinical trial, low-dose colchicine use was as comparably effective as the high-dose colchicine in gout flare with minimal side effects, and therefore, low-dose colchicine has been recommended for use in gout flare prophylaxis and therapy [97]. The question remains, whether low-dose colchicine use remains effective and safe, for treatment of flares or flare prophylaxis, in those with advanced CKD. Similarly, we do not have adequate efficacy and safety outcome data for IL-1 inhibitor use in gout flare and CKD to inform clinicians if renally adjusted dosing is required when using these IL-1 inhibitors for different renal disease severity. The issue of IL-1 inhibition use for flare prophylaxis in patients with gout and advanced CKD remains essentially unexplored. Additionally, from the pharmacovigilance perspective, drug tolerance is an important consideration when using these anti-inflammatory medications in gout flare. For colchicine, increased drug toxicity is seen in individuals with CKD, due to increased drug half-life. In addition, the overall colchicine-related side effects secondary to drug retention are more noticeable when treating gout flare transiently in the clinical settings of concomitant CKD and acute illness such as dehydration and sepsis. It is also important to note that colchicine use in gout and advanced CKD can be hazardous when used in conjunction with some medications, such as statin therapies (CYP3A4 inhibitors), cyclosporin (both CYP3A4 and P-glycoprotein inhibitors), and macrolide antibiotic, such as clarithromycin (both CYP3A4 and Pglycoprotein inhibitors). Similarly, for anakinra, the dose should be renally adjusted in individuals with gout and advanced CKD due to the risk of increased drug halflife, and yet, this recommendation is seldom applied in the clinical practice.

In the case of NSAID use as gout flare prophylaxis and therapy, we did not expect to find any recent data to justify NSAID use in CKD, as all NSAIDs are widely known to be contraindicated in advanced CKD. Indeed, the included case series/reports of NSAID use in this review favourably justify the avoidance of any NSAID use in individuals with gout and renal failure. Almost all studies found were only aiming at highlighting the nephrotoxic risk of NSAID use in this high-risk comorbid population with gout flare. The question remains, however, as to whether NSAID use is equally effective and safe in patients with non-residual renal function compared with those with normal renal function but we did not find any published evidence to support or refute that hypothesis. In the case of glucocorticoid use, all studies found described either refractory or very severe gout flare cases, which are not necessarily reflecting the common clinical practice of gout flare management. We did not find studies exploring the question of whether low doses of glucocorticoids could be part of the prophylaxis of gout flares. Another question that remains is whether glucocorticoid use is equally effective and safe or if there is a potential risk of exacerbating tophaceous gout disease.

Furthermore, we found that all clinical trials reported pooled data on efficacy and/or safety outcomes, even with renal function stratified at baseline for all study participants. Pertinent to our review aims, it is evident that most clinical trials of gout flare prophylaxis and therapy excluded study participants with advanced CKD (i.e. CKD $\geq$ stage 3 ). This is likely explained by the strict regulations implemented in most clinical trial approval by the US Food and Drug Administration (FDA) and the European Medicines Agency (EMA), of which these regulatory bodies restrict the inclusion of study participants with $C K D \geq$ stage 3 . In terms of profiling drug safety in the management of gout flare, we identified certain side effects being reported in the studies, but unlikely to have any attribution to the underlying renal impairment. For example, infections were commonly reported for IL-1 inhibitors and glucocorticoid use, which would be likely due to the immunomodulatory effects from the drug use, rather than the effects of the underlying reduced renal function. This finding highlights the importance of profiling drug safety with the comparison between individuals with and without CKD in gout studies, where possible.

This review has highlighted the heterogenous patterns in efficacy and/or safety outcome reporting in all studies on gout flare management and prophylaxis, irrespective of the study designs. This observation is also echoed by a recent systematic review by Stewart and colleagues on gout flare reporting in clinical trials [98]. Besides the patient's self-reported gout flare resolution and other symptom reporting, objective assessments such as using the pain visual analogue score (VAS) and C-reactive protein (CRP) level are commonly implemented in the study protocols in evaluating treatment efficacy in most clinical trials and observational studies of gout flare management. Yet, these objective assessments are not necessarily standardised among clinical trials and the gout flare definition may differ between studies. Such issues can further complicate the interpretation of study findings when comparisons between studies are made collectively. A recent validation study in defining gout flare by Gaffo and colleagues has stressed the importance of having an accurate and validated definition and assessment of gout flare in all clinical studies of gout [99]. By incorporating standardised gout flare definition in future gout flare studies, comparisons in treatment outcomes across studies of different treatments used as gout flare prophylaxis and therapy can be performed fairly and efficiently. Ideally, the efficacy and safety of gout flare and 
urate-lowering treatments based on stratified renal function should be emphasised in all gout studies, as gout and CKD often co-exist. For example, an ongoing Veterans Affairs (VA) StopGOUT study in the USA is currently evaluating the 'treat-to-target' dose escalation of urate-lowering therapies (allopurinol versus febuxostat) in managing gout and with further observation in assessing the efficacy and safety of renally adjusted dosing in study participants with co-existing CKD [100].

This review has some study limitations. We did not include non-English published studies or unpublished data, which could potentially lead to bias in the study inclusion and exclusion process. Specifically, relevant information on the use of IL-1 inhibitors may be missed, considering that anakinra is an off-label use for gout flare therapy in some countries and canakinumab is not widely indicated for gout flare therapy in some Englishspeaking countries. We did not have sufficient data for people with gout flare and underlying renal transplant, and therefore, the findings from this review may not reflect on this specific renal disease subgroup. Due to the heterogeneity nature of the study designs across all included studies, quantitative analysis such as metaanalysis could not be performed. In general, we propose that the overall findings and interpretations of this review using the best evidence synthesis approach is unlikely to differ despite our study limitations.

\section{Conclusion}

In summary, this review has described the current literature on the efficacy and safety of gout flare prophylaxis and therapy use in people with gout and concomitant CKD. The dearth of high-quality data reporting in this high-risk comorbid population is concerning, especially in clinical trials. Currently, treating clinicians have no evidence-based approaches to manage flares or prophylaxis in patients with gout and advanced CKD. Current and future gout flare studies should include patients with CKD and inform study results stratified by renal function as well as using standardised gout flare definitions in the study design. With these key steps, results of future gout flare prophylaxis and treatment studies will guide better and systematic evidence-informed approach in managing gout flares and prophylaxis in patients with advanced CKD.

\section{Supplementary Information}

The online version contains supplementary material available at https://doi. org/10.1186/s13075-021-02416-y.

Additional file 1.

\section{Abbreviations}

ACR: American College of Rheumatology; AKI: Acute kidney injury; CKD: Chronic kidney disease; CrCL: Creatinine clearance; CRP: C-reactive protein; eGFR: Estimated glomerular filtration rate; EMA: European Medicines Agency; ESRD: End-stage renal disease; EULAR: European League Against Rheumatism; FDA: Federal Drug Administration; G-CAN: Gout, Hyperuricemia and Crystal-Associated Disease Network; IL: Interleukin; NSAIDs: Non-steroidal anti-inflammatory drugs; PRISMA: Preferred Reporting Items for systematic Reviews and Meta-Analyses; RCTs: Randomised controlled trials; ULT: Uratelowering therapy; VAS: Visual analogue scale

\section{Acknowledgements}

The authors would like to acknowledge the invaluable contribution of Ms. Carolyn Holmes from the University of Alabama at Birmingham Lister Hill Library for her assistance with the literature searches needed for this systematic review.

\section{Authors' contributions}

HLP — data acquisition and data analysis manuscript preparation MCF-data acquisition and data analysis manuscript preparation HF-data acquisition and data analysis manuscript preparation ABV_-data acquisition and data analysis manuscript preparation $\mathrm{CLH}$ - protocol development, data acquisition, and data analysis manuscript preparation LKS - protocol development, data acquisition, and data analysis manuscript preparation AG_-protocol development, data acquisition, and data analysis manuscript preparation. The authors read and approved the final manuscript.

\section{Funding}

This research did not receive any specific grant from funding agencies in the public, commercial, or not-for-profit sectors.

\section{Availability of data and materials}

All data are in the manuscript and supplementary files.

\section{Ethics approval and consent to participate}

N/A.

\section{Consent for publication}

N/A.

\section{Competing interests}

All authors declared no conflict of interests. G-Can is supported at arm's length unrestricted by grants from pharma companies in last 12 months that was horizon and Astra Zeneca and LG.

\section{Author details}

${ }^{1}$ Discipline of Medicine, Faculty of Health and Medical Sciences, the University of Adelaide, Adelaide, South Australia, Australia. ${ }^{2}$ Harvard Medical School and Massachusetts General Hospital, Boston, MA, USA. ${ }^{3}$ Prima CARE, Fall River, MA, USA. ${ }^{4}$ Department of Medicine, University of Otago,

Christchurch, New Zealand. ${ }^{5}$ Department of Internal Medicine, Rio de Janeiro State University, Rio de Janeiro, Brazil. ${ }^{6}$ Rheumatology Unit, The Queen Elizabeth Hospital, Woodville South, South Australia, Australia. ${ }^{7}$ Division of Rheumatology and Clinical Immunology, University of Alabama, 1720 2nd Avenue South, Birmingham, AL 35294, USA. ${ }^{8}$ Birmingham VA Medical Center, Birmingham, USA.

Received: 18 October 2020 Accepted: 4 January 2021

Published online: 28 April 2021

\section{References}

1. Kuo CF, Grainge MJ, Zhang W, Doherty M. Global epidemiology of gout: prevalence, incidence and risk factors. Nat Rev Rheumatol. 2015;11(11):64962. https://doi.org/10.1038/nrrheum.2015.91

2. Stamp LK, Chapman PT. Gout and its comorbidities: implications for therapy. Rheumatology (Oxford). 2013;52(1):34-44. https://doi.org/10.1093/ rheumatology/kes211.

3. Zhu Y, Pandya BJ, Choi HK. Comorbidities of gout and hyperuricemia in the US general population: NHANES 2007-2008. Am J Med. 2012;125(7):679-87 e1. https://doi.org/10.1016/j.amjmed.2011.09.033.

4. Krishnan E. Reduced glomerular function and prevalence of gout: NHANES 2009-10. PLoS One. 2012;7(11):e50046. https://doi.org/10.1371/journal.pone. 0050046. 
5. Terkeltaub R. What makes gouty inflammation so variable? BMC Med. 2017; 15(1):158. https://doi.org/10.1186/s12916-017-0922-5.

6. FitzGerald JD, Dalbeth N, Mikuls T, Brignardello-Petersen R, Guyatt G, Abeles AM, et al. American College of Rheumatology Guideline for the management of gout. Arthritis Care Res. 2020;2020. https://doi.org/10.1002/ acr.24180.

7. Vargas-Santos $A B$, Neogi T. Management of gout and hyperuricemia in CKD. Am J Kidney Dis. 2017;70(3):422-39. https://doi.org/10.1053/j.ajkd. 2017.01.055.

8. Stewart S, Yang KCK, Atkins K, Dalbeth N, Robinson PC. Adverse events during oral colchicine use: a systematic review and meta-analysis of randomised controlled trials. Arthritis Res Ther. 2020;22(1):28. https://doi.org/ 10.1186/s13075-020-2120-7.

9. Ahern MJ, Reid C, Gordon TP, McCredie M, Brooks PM, Jones M. Does colchicine work? The results of the first controlled study in acute gout. Aust NZ J Med. 1987;17(3):301-4. https://doi.org/10.1111/j.1445-5994.1987. tb01232.x.

10. Borstad GC, Bryant LR, Abel MP, Scroggie DA, Harris MD, Alloway JA. Colchicine for prophylaxis of acute flares when initiating allopurinol for chronic gouty arthritis. J Rheumatol. 2004;31(12):2429-32.

11. Wortmann RL, Macdonald PA, Hunt B, Jackson RL. Effect of prophylaxis on gout flares after the initiation of urate-lowering therapy: analysis of data from three phase III trials. Clin Ther. 2010;32(14):2386-97. https://doi.org/10. 1016/j.clinthera.2011.01.008.

12. Pascart T, Lancrenon S, Lanz S, Delva C, Guggenbuhl P, Lambert C, et al. GOSPEL 2 - colchicine for the treatment of gout flares in France - a GOSPEL survey subgroup analysis. Doses used in common practices regardless of renal impairment and age. Joint Bone Spine. 2016;83(6):687-93. https://doi. org/10.1016/j.jbspin.2015.10.006.

13. Solak Y, Atalay H, Biyik Z, Alibasic H, Gaipov A, Guney F, et al. Colchicine toxicity in end-stage renal disease patients: a case-control study. Am J Ther. 2014;21(6):e189-95. https://doi.org/10.1097/MJT. Ob013e31825a364a.

14. Hung IF, Wu AK, Cheng VC, Tang BS, To KW, Yeung CK, et al. Fatal interaction between clarithromycin and colchicine in patients with renal insufficiency: a retrospective study. Clin Infect Dis. 2005:41(3):291-300. https://doi.org/10.1086/431592.

15. Kwon OC, Hong S, Ghang B, Kim YG, Lee CK, Yoo B. Risk of colchicineassociated myopathy in gout: influence of concomitant use of statin. Am J Med. 2017;130(5):583-7. https://doi.org/10.1016/j.amjmed.2016.12.006.

16. Akar A, Bulent Tastan H, Erbil H, Arca E, Kurumlu Z, Gur AR. Efficacy and safety assessment of $0.5 \%$ and $1 \%$ colchicine cream in the treatment of actinic keratoses. J Dermatolog Treat. 2001;12(4):199-203. https://doi.org/10. 1080/09546630152696314.

17. Akdag I, Ersoy A, Kahvecioglu S, Gullulu M, Dilek K. Acute colchicine intoxication during clarithromycin administration in patients with chronic renal failure. J Nephrol. 2006;19(4):515-7.

18. Alayli G, Cengiz K, Canturk F, Durmus D, Akyol Y, Menekse EB. Acute myopathy in a patient with concomitant use of pravastatin and colchicine. Ann Pharmacother. 2005;39(7-8):1358-61. https://doi.org/10.1345/aph.1E593.

19. Altiparmak MR, Pamuk ON, Pamuk GE, Hamuryudan V, Ataman R, Serdengecti K. Colchicine neuromyopathy: a report of six cases. Clin Exp Rheumatol. 2002:20(4 Suppl 26):S13-6.

20. Altman A, Szyper-Kravitz M, Shoenfeld Y. Colchicine-induced rhabdomyolysis. Clin Rheumatol. 2007;26(12):2197-9. https://doi.org/10. 1007/s10067-007-0682-2.

21. Baker SK, Goodwin S, Sur M, Tarnopolsky MA. Cytoskeletal myotoxicity from simvastatin and colchicine. Muscle Nerve. 2004;30(6):799-802. https://doi. org/10.1002/mus.20135.

22. Bonnel RA, Villalba ML, Karwoski CB, Beitz J. Deaths associated with inappropriate intravenous colchicine administration. J Emerg Med. 2002; 22(4):385-7. https://doi.org/10.1016/s0736-4679(02)00430-4.

23. Boomershine $\mathrm{KH}$. Colchicine-induced rhabdomyolysis. Ann Pharmacother. 2002;36(5):824-6. https://doi.org/10.1345/aph.1A288.

24. Bouquie R, Deslandes G, Renaud C, Dailly E, Haloun A, Jolliet P. Colchicineinduced rhabdomyolysis in a heart/lung transplant patient with concurrent use of cyclosporin, pravastatin, and azithromycin. J Clin Rheumatol. 2011; 17(1):28-30. https://doi.org/10.1097/RHU.0b013e3182056042.

25. Cheng VC, Ho PL, Yuen KY. Two probable cases of serious drug interaction between clarithromycin and colchicine. South Med J. 2005;98(8):811-3. https://doi.org/10.1097/01.SMJ.0000163315.02563.B2.
26. Choi SS, Chan KF, Ng HK, Mak WP. Colchicine-induced myopathy and neuropathy. Hong Kong Med J. 1999;5(2):204-7.

27. Dixon AJ, Wall GC. Probable colchicine-induced neutropenia not related to intentional overdose. Ann Pharmacother. 2001;35(2):192-5. https://doi.org/ 10.1345/aph.10184.

28. Eleftheriou G, Bacis G, Fiocchi R, Sebastiano R. Colchicine-induced toxicity in a heart transplant patient with chronic renal failure. Clin Toxicol (Phila). 2008;46(9):827-30. https://doi.org/10.1080/15563650701779703.

29. Garrouste C, Philipponnet C, Kaysi S, Enache I, Tiple A, Heng AE. Severe colchicine intoxication in a renal transplant recipient on cyclosporine. Transplant Proc. 2012;44(9):2851-2. https://doi.org/10.1016/j.transproceed. 2012.09.028.

30. Hsu WC, Chen WH, Chang MT, Chiu HC. Colchicine-induced acute myopathy in a patient with concomitant use of simvastatin. Clin Neuropharmacol. 2002;25(5):266-8. https://doi.org/10.1097/00002826200209000-00008.

31. Huh K, Joung JY, Jeong H, Je D, Cho YY, Jang HR, et al. Colchicine-induced myoneuropathy in a cyclosporine-treated renal transplant recipient. Kidney Res Clin Pract. 2013;32(2):74-7. https://doi.org/10.1016/j.krcp.2013.04.003.

32. Justiniano M, Dold S, Espinoza LR. Rapid onset of muscle weakness (rhabdomyolysis) associated with the combined use of simvastatin and colchicine. J Clin Rheumatol. 2007;13(5):266-8. https://doi.org/10.1097/RHU. ob013e318156d977.

33. Kubler PA. Fatal colchicine toxicity. Med J Aust. 2000;172(10):498-9.

34. Kuncl RW, Duncan G, Watson D, Alderson K, Rogawski MA, Peper M. Colchicine myopathy and neuropathy. N Engl J Med. 1987;316(25):1562-8. https://doi.org/10.1056/NEJM198706183162502.

35. Lai IC, Cheng CY, Chen HH, Chen WY, Chen PY. Colchicine myoneuropathy in chronic renal failure patients with gout. Nephrology (Carlton). 2006;11(2): 147-50. https://doi.org/10.1111/j.1440-1797.2006.00542.x.

36. Lee BI, Shin SJ, Yoon SN, Choi YJ, Yang CW, Bang BK. Acute myopathy induced by colchicine in a cyclosporine-treated renal transplant recipient--a case report and review of the literature. J Korean Med Sci. 1997;12(2):160-1. https://doi.org/10.3346/jkms.1997.12.2.160.

37. Ly J, Gow P, Dalbeth N. Colchicine prescribing and safety monitoring in patients with gout. N Z Med J. 2007:120(1265):U2808.

38. Marciniak C, Babu A, Ghannad L, Burnstine R, Keeshin S. Unusual electromyographic findings associated with colchicine neuromyopathy: a case report. PM R. 2016;8(10):1016-9. https://doi.org/10.1016/j.pmrj.2016.03. 003.

39. Medani S, Wall C. Colchicine toxicity in renal patients - are we paying attention? Clin Nephrol. 2016;86(2):100-5. https://doi.org/10.5414/CN108343.

40. Montseny JJ, Meyrier A, Gherardi RK. Colchicine toxicity in patients with chronic renal failure. Nephrol Dial Transplant. 1996;11(10):2055-8. https://doi. org/10.1093/oxfordjournals.ndt.a027096.

41. Morris I, Varughese G, Mattingly P. Colchicine in acute gout. BMJ. 2003: 327(7426):1275-6. https://doi.org/10.1136/bmj.327.7426.1275.

42. Mullins M, Cannarozzi AA, Bailey TC, Ranganathan P. Unrecognized fatalities related to colchicine in hospitalized patients. Clin Toxicol (Phila). 2011;49(7): 648-52. https://doi.org/10.3109/15563650.2011.589844.

43. Nashel DJ, Chandra M. Acute gouty arthritis. Special management considerations in alcoholic patients. JAMA. 1982;247(1):58-9. https://doi.org/ 10.1001/jama.247.1.58

44. Neuss MN, McCallum RM, Brenckman WD, Silberman HR. Long-term colchicine administration leading to colchicine toxicity and death. Arthritis Rheum. 1986;29(3):448-9. https://doi.org/10.1002/art.1780290324.

45. Ortel RW, Newcombe DS. Acute gouty arthritis and response to colchicine in the virtual absence of synovial-fluid leukocytes. N Engl J Med. 1974; 290(24):1363-4. https://doi.org/10.1056/NEJM197406132902406.

46. Patel S, Andres J, Qureshi K. An unexpected interaction between sofosbuvir/ ledipasvir and atorvastatin and colchicine causing rhabdomyolysis in a patient with impaired renal function. Case Rep Med. 2016;2016:3191089. https://doi.org/10.1155/2016/3191089

47. Petersel D, Schlesinger $N$. Treatment of acute gout in hospitalized patients. J Rheumatol. 2007;34(7):1566-8.

48. Rana SS, Giuliani MJ, Oddis CV, Lacomis D. Acute onset of colchicine myoneuropathy in cardiac transplant recipients: case studies of three patients. Clin Neurol Neurosurg. 1997:99(4):266-70. https://doi.org/10.1016/ s0303-8467(97)00092-9.

49. Rieger EH, Halasz NA, Wahlstrom HE. Colchicine neuromyopathy after renal transplantation. Transplantation. 1990;49(6):1196-8. 
50. Rutkove SB, De Girolami U, Preston DC, Freeman R, Nardin RA, Gouras GK, et al. Myotonia in colchicine myoneuropathy. Muscle Nerve. 1996;19(7):8705. https://doi.org/10.1002/(SICI)1097-4598(199607)19:7<870::AID-MUS9>3.0. CO;2-6.

51. Su YC, Wu CC. Colchicine-induced acute neuromyopathy in a patient using concomitant fluconazole: case report and literature review. Drug Saf Case Rep. 2015;2(1):16. https://doi.org/10.1007/s40800-015-0020-6.

52. van der Velden W, Huussen J, Ter Laak H, de Sevaux R. Colchicine-induced neuromyopathy in a patient with chronic renal failure: the role of clarithromycin. Neth J Med. 2008;66(5):204-6.

53. Wilbur K, Makowsky M. Colchicine myotoxicity: case reports and literature review. Pharmacotherapy. 2004;24(12):1784-92. https://doi.org/10.1592/ phco.24.17.1784.52334

54. Wright S, Chapman PT, Frampton C, O'Donnell JL, Raja R, Stamp LK. Management of gout in a hospital setting: a lost opportunity. J Rheumatol. 2017:44(10):1493-8. https://doi.org/10.3899/jrheum.170387.

55. Yoon $\mathrm{KH}$. Colchicine induced toxicity and pancytopenia at usual doses and treatment with granulocyte colony-stimulating factor. J Rheumatol. 2001; 28(5):1199-200.

56. Yu J, Qiu Q, Liang L, Yang X, Xu H. Prophylaxis of acute flares when initiating febuxostat for chronic gouty arthritis in a real-world clinical setting. Mod Rheumatol. 2018;28(2):339-44. https://doi.org/10.1080/ 14397595.2017 .1318467

57. Zagler B, Kaneppele A, Pattis P, Stockner I, Sitzmann G, Widmann J, et al. Patient risk factors and adverse drug interactions in the treatment of acute gouty arthritis in the elderly: a case report. Cases J. 2009;2:6602. https://doi. org/10.1186/1757-1626-2-6602.

58. Schlesinger N, De Meulemeester M, Pikhlak A, Yucel AE, Richard D, Murphy $V$, et al. Canakinumab relieves symptoms of acute flares and improves health-related quality of life in patients with difficult-to-treat gouty arthritis by suppressing inflammation: results of a randomized, dose-ranging study. Arthritis Res Ther. 2011;13(2):R53. https://doi.org/10.1186/ar3297.

59. Schlesinger N, Alten RE, Bardin T, Schumacher HR, Bloch M, Gimona A, et al. Canakinumab for acute gouty arthritis in patients with limited treatment options: results from two randomised, multicentre, active-controlled, double-blind trials and their initial extensions. Ann Rheum Dis. 2012;71(11): 1839-48. https://doi.org/10.1136/annrheumdis-2011-200908.

60. So A, De Smedt T, Revaz S, Tschopp J. A pilot study of IL-1 inhibition by anakinra in acute gout. Arthritis Res Ther. 2007;9(2):R28. https://doi.org/10. 1186/ar2143.

61. So A, De Meulemeester M, Pikhlak A, Yucel AE, Richard D, Murphy V, et al. Canakinumab for the treatment of acute flares in difficult-to-treat gouty arthritis: results of a multicenter, phase II, dose-ranging study. Arthritis Rheum. 2010;62(10):3064-76. https://doi.org/10.1002/art.27600.

62. Sunkureddi P, Bardin T, Alten RE, Schlesinger $N$, Bloch $M$, Kiechle T, et al. Effect of IL-1 inhibition with canakinumab compared to triamcinolone acetonide on pain intensity and new flares in gouty arthritis patients with chronic kidney disease stage 2-5. Arthritis Rheum. 2011;63.

63. Sunkureddi $P$, Bardin T, Alten RE, Schlesinger $N$, Bloch M, Kiechle T, et al. Efficacy and safety of canakinumab in gouty arthritis patients with chronic kidney disease stage $\geq 3$. Ann Rheum Dis. 2013;2013:447.

64. Sunkureddi P, Toth E, Brown J, Kivitz A, Stancati A, Richard D, et al. Efficacy and safety of canakinumab pre-filled syringe in acute gouty arthritis patients with chronic kidney disease stage $\geq 3$. Arthritis Rheum. 2014;73:1083.

65. Terkeltaub R, Sundy JS, Schumacher HR, Murphy F, Bookbinder S, Biedermann $\mathrm{S}$, et al. The interleukin 1 inhibitor rilonacept in treatment of chronic gouty arthritis: results of a placebo-controlled, monosequence crossover, non-randomised, single-blind pilot study. Ann Rheum Dis. 2009; 68(10):1613-7. https://doi.org/10.1136/ard.2009.108936

66. Terkeltaub R, Evans RR, Weinstein SP, Wu R, Schumacher HR. Rilonacept for gout flare prophylaxis in patients with chronic kidney disease: analysis of 3 clinical trials. Arthritis Rheum. 2012:64.

67. Adler S, Seitz M. The gouty spine: old guy-new tricks. Rheumatology (Oxford). 2017;56(12):2243-5. https://doi.org/10.1093/rheumatology/kex325.

68. Aouba A, Deshayes S, Frenzel L, Decottignies A, Pressiat C, Bienvenu B, et al. Efficacy of anakinra for various types of crystal-induced arthritis in complex hospitalized patients: a case series and review of the literature. Mediat Inflamm. 2015:2015:792173. https://doi.org/10.1155/2015/792173.

69. Bartov JB, Ali Y. Successful use of the interleukin 1 antagonist, anakinra, in a patient with gout, chronic kidney disease, and aplastic anemia. J Clin Rheumatol. 2013;19(8):454-6. https://doi.org/10.1097/RHU.0000000000000047.
70. Chen K, Fields T, Mancuso CA, Bass AR, Vasanth L. Anakinra's efficacy is variable in refractory gout: report of ten cases. Semin Arthritis Rheum. 2010; 40(3):210-4. https://doi.org/10.1016/j.semarthrit.2010.03.001.

71. Direz G, Noel N, Guyot C, Toupance O, Salmon JH, Eschard JP. Efficacy but side effects of anakinra therapy for chronic refractory gout in a renal transplant recipient with preterminal chronic renal failure. Joint Bone Spine. 2012;79(6):631. https://doi.org/10.1016/j.jbspin.2012.04.009.

72. Donmez S, Pamuk ON. Chronic tophaceous gout. J Rheumatol. 2014;41(3): 554-5. https://doi.org/10.3899/jrheum.130688.

73. Funck-Brentano T, Salliot C, Leboime A, Zafrani L, Servais A, Larousserie F, et al. First observation of the efficacy of IL-1 ra to treat tophaceous gout of the lumbar spine. Rheumatology (Oxford). 2011;50(3):622-4. https://doi.org/10. 1093/rheumatology/keq358.

74. Ghosh P, Cho M, Rawat G, Simkin PA, Gardner GC. Treatment of acute gouty arthritis in complex hospitalized patients with anakinra. Arthritis Care Res. 2013;65(8):1381-4. https://doi.org/10.1002/acr.21989.

75. Gratton SB, Scalapino KJ, Fye KH. Case of anakinra as a steroid-sparing agent for gout inflammation. Arthritis Rheum. 2009;61(9):1268-70. https://doi.org/ 10.1002/art.24694.

76. Loustau C, Rosine N, Forien M, Ottaviani S, Juge PA, Liote F, et al. Effectiveness and safety of anakinra in gout patients with stage 4-5 chronic kidney disease or kidney transplantation: a multicentre, retrospective study. Joint Bone Spine. 2018;85(6):755-60. https://doi.org/10.1016/j.jbspin.2018.03. 015.

77. Marotto D, De Santis A, Chessa D, Firinu D, Del Giacco S. A Beacon in the dark: canakinumab. A new therapeutic perspective in chronic tophaceous gout. Rheumatol Ther. 2018;5(1):303-10. https://doi.org/10.1007/s40744-0180104-8.

78. McGonagle D, Tan AL, Shankaranarayana S, Madden J, Emery P, McDermott MF. Management of treatment resistant inflammation of acute on chronic tophaceous gout with anakinra. Ann Rheum Dis. 2007;66(12):1683-4. https://doi.org/10.1136/ard.2007.073759.

79. Ottaviani S, Molto A, Ea HK, Neveu S, Gill G, Brunier L, et al. Efficacy of anakinra in gouty arthritis: a retrospective study of 40 cases. Arthritis Res Ther. 2013;15(5):R123. https://doi.org/10.1186/ar4303.

80. Palma C, Topping T, Tabechian D. Anakinra is effective and well tolerated in medically complex patients including transplant recipients with gout. Arthritis Rheum. 2016

81. Perez-Ruiz F, Herrero-Beites AM, Alonso-Ruiz A, Atxotegi J, Lopez-Santamaria MR, de Miguel M. Low-dose anakinra is effective for the prophylaxis of acute episodes of inflammation in severe tophaceous gout. Ann Rheum Dis. 2013;72:A707.

82. Singh $\mathrm{D}$, Huston $\mathrm{KK}$. IL-1 inhibition with anakinra in a patient with refractory gout. J Clin Rheumatol. 2009;15(7):366. https://doi.org/10.1097/RHU. Ob013e3181be2423.

83. Tran AP, Edelman J. Interleukin-1 inhibition by anakinra in refractory chronic tophaceous gout. Int J Rheum Dis. 2011;14(3):e33-7. https://doi.org/10.1111/ j.1756-185X.2011.01629.x.

84. Kahl LE, Thompson ME, Griffith BP. Gout in the heart transplant recipient: physiologic puzzle and therapeutic challenge. Am J Med. 1989;87(3):289-94. https://doi.org/10.1016/s0002-9343(89)80153-6.

85. Mikhnevich $\mathrm{E}$, Lemiasheuskaya S. Factors associated with refractoriness to NSAIDS in GOUTY arthritis. Ann Rheum Dis. 2013;71:444.

86. Schlondorff D. Renal complications of nonsteroidal anti-inflammatory drugs. Kidney Int. 1993;44(3):643-53. https://doi.org/10.1038/ki.1993.293.

87. Bajaj S, Fessler BJ, Alarcon GS. Systemic lupus erythematosus and gouty arthritis: an uncommon association. Rheumatology (Oxford). 2004;43(3):34952. https://doi.org/10.1093/rheumatology/keh043.

88. Fargetti S, Goldenstein-Schainberg C, Silva Abreu A, Fuller R. Refractory gout attack. Case Rep Med. 2012;2012:657694. https://doi.org/10.1155/2012/ 657694.

89. Hausch R, Wilkerson M, Singh E, Reyes C, Harrington T. Tophaceous gout of the thoracic spine presenting as back pain and fever. J Clin Rheumatol. 1999:5(6):335-41. https://doi.org/10.1097/00124743-199912000-00007.

90. Hill CL, Lu TY, Cervelli M, Mathew T. Failure of rasburicase therapy in recurrent acute gout with tophi. Int J Rheum Dis. 2008;2008(11):315-7.

91. Karimzadeh H, Mohtasham N, Karimifar M, Salesi M, Bonakdar ZS. A case of ochronosis with gout and Monckeberg arteries. Rheumatol Int. 2009;29(12): 1507-10. https://doi.org/10.1007/s00296-009-0882-y.

92. Maekawa M, Tomida H, Aoki T, Hishida M, Morinaga T, Tamai H. Successful treatment of refractory gout using combined therapy consisting of 
febuxostat and allopurinol in a patient with chronic renal failure. Intern Med. 2014;53(6):609-12. https://doi.org/10.2169/internalmedicine.53.0698.

93. Richette P, Bardin T. Successful treatment with rasburicase of a tophaceous gout in a patient allergic to allopurinol. Nat Clin Pract Rheumatol. 2006;2(6): 338-42; quiz 43. https://doi.org/10.1038/ncprheum0214.

94. Sarmento JF, Cavalcante VDA, M.T.R. S, Braz ADS, Freire EAM. Chronic tophaceous gout mimicking rheumatoid arthritis. Rev Bras Reumatol. 2009; 49:741-6.

95. Tausche AK, Wunderlich C, Aringer M. Tophaceous gout and rena insufficiency: a new solution for an old therapeutic dilemma. Case Rep Med. 2011;2011:397646. https://doi.org/10.1155/2011/397646.

96. Udayakumar D, Kteleh T, Alfata S, Bali T, Joseph A. Spinal gout mimicking paraspinal abscess: a case report. J Radiol Case Rep. 2010;4(6):15-20. https:// doi.org/10.3941/jrcr.v4i6.332.

97. Terkeltaub RA, Furst DE, Bennett K, Kook KA, Crockett RS, Davis MW. High versus low dosing of oral colchicine for early acute gout flare: twenty-fourhour outcome of the first multicenter, randomized, double-blind, placebocontrolled, parallel-group, dose-comparison colchicine study. Arthritis Rheum. 2010;62(4):1060-8. https://doi.org/10.1002/art.27327.

98. Stewart S, Tallon A, Taylor WJ, Gaffo A, Dalbeth N. How flare prevention outcomes are reported in gout studies: a systematic review and content analysis of randomized controlled trials. Semin Arthritis Rheum. 2020;50(2): 303-13. https://doi.org/10.1016/j.semarthrit.2019.11.002

99. Gaffo AL, Dalbeth N, Saag KG, Singh JA, Rahn EJ, Mudano AS, et al. Brief report: validation of a definition of flare in patients with established gout. Arthritis Rheum. 2018;70(3):462-7. https://doi.org/10.1002/art.40381.

100. Timilsina S, Brittan K, O'Dell JR, Brophy M, Davis-Karim A, Henrie AM, et al. Design and rationale for the veterans affairs "cooperative study program 594 comparative effectiveness in gout: allopurinol vs. febuxostat" trial. Contemp Clin Trials. 2018;68:102-8. https://doi.org/10.1016/j.cct.2018.03.015.

\section{Publisher's Note}

Springer Nature remains neutral with regard to jurisdictional claims in published maps and institutional affiliations. 